\section{THE FOUR-HORNED ANTELOPE OR CHOUSINGHA (TETRACEROS QUADRICORNIS) IN SIMILIPAL}

\author{
L.A.K. Singh ${ }^{1}$ and Debabrata Swain ${ }^{2}$ \\ Similipal Tiger Reserve, Baripada, Orissa 757002, India. \\ Email:1'bid_lashvini@sancharnet.in, ${ }^{2}$ bid_simitig@sancharnet.in
}

Prater (1971) mentioned the distribution of Chousingha or Fourhorned Antelope (FHA), Tetraceros quadricornis as peninsular India south of the Himalaya where the country is wooded and hilly, but not too densely forested, and that it was not found on the Malabar Coast. Ranjitsinh (1987) reported that the range of Chousingha extends from the Terai forests and Jammu to Mudumalai Sanctuary in Tamil Nadu, though in the past it was reported even in the Palani Hills, and that it occurs in the Barda and Gir forests of Gujarat, extending eastwards to Bihar. It was never reported to occur in Orissa. Rice (1991) conducted a questionnaire survey on the status of FHA in 1986-1987 and cited the information gathered from Orissa through the questionnaire.

The state of Orissa is known to have populations of FHA in Badrama Sanctuary, Chandaka Dampada Sanctuary, Kotagarh Sanctuary, Satkoshia Gorge Sanctuary and Similipal Sanctuary. FHA is locally extinct in Karlapat Sanctuary (Mishra et al., 1996). The present note consolidates information on Chowsingha of Similipal available in literature, management plan and records of the first author during the 15 years period 1987-2002.

During early 1970s the Four-horned Antelope occurred in Similipal in open wood lands along the edge of large valleys to the south (Choudhury, 1974). During a reconnaissance survey in Bachurichara Valley in May 1972, two FHAs were seen and in May 1973 five dung-heaps were found.

From November 1987 to January 2002 information on Chousingha was collected through different sources. These are from direct observations of Chousingha, observations of their dung heaps, and second-hand information made available by staff through their 'diary'. The first author sighted Chousingha near Nigirda-Panasia stretch in central Similipal and near Bachhurichara Valley in the south. Other information include their availability near Panasia, Dhudruchampa, western part of Sunpokhri, Tarinivilla, Nuagaon, Devasthali, Patbil and Bhanjabasa. Dung heaps are best seen in Bachhurichara and Debasthali valleys. All the locations represent the south-central and southern parts of the core zone of Similipal Tiger Reserve (Fig. 1).

The Chousingha population of Similipal assumes significance from two respects. First, it is within the eastern-most limit for the species in the state of Orissa that remained unnoticed for a long time, and second, the population is very small, perhaps about a hundred heads, in the reserve.

FHA is included under Schedule I of the Wildlife (Protection) Act, 1972 (Anon, 1997). Rice (1991) reported that since FHA occurs in low densities and small population sizes, and has attracted little scientific attention, it was necessary to have trial efforts for techniques in genetic monitoring and conservation management.

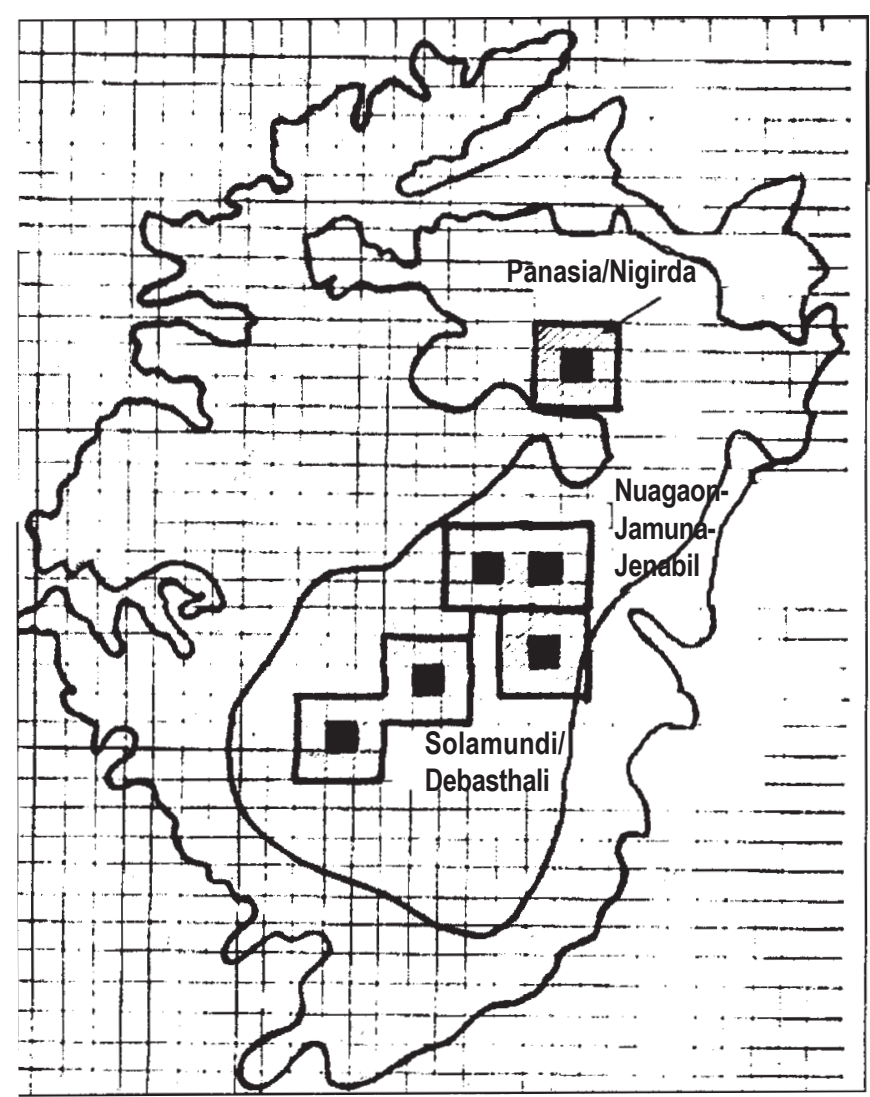

Figure 1. Sightings and pellet evidences of Chousingha Tetraceros quadricornis in Similipal Tiger Reserve 
The population of FHA in Similipal Tiger Reserve forms an example to the concern expressed by Rice (1991) that with intensification and spread of human impacts FHA populations are becoming increasingly isolated. The rate of the sighting of FHA in Similipal has become occasional, and the population is subjected to adverse human impacts. Yet, FHA is considered to be safer in Similipal than anywhere else in its eastern ranges because of various management practices implemented under Project Tiger, Project Elephant, Biosphere Reserve and Ecodevelopment Scheme.

\section{References}

Anon (1997). The Wildlife (Projection) Act, 1972 (as amended up to 1993). Natraj Publishers, Dehra Dun in Technical Association with Traffic, India.

Choudhury, S.R. (1974). Management Plan of Similipal Tiger Reserve, pp.11-12.

Frankel, O.H. and M.E. Soule (1981). Conservation and Evolution. Cambridge University Press, Cambridge.

Mishra, C.H.G., S.K. Patnaik, S.K. Sinha, S.K. Kar, C.S. Kar and L.A.K. Singh (1996). Wildlife Wealth of Orissa. Forest Department, Wildlife Wing, 185pp.

Prater, S.H. (1971). The Book of Indian Animals. Bombay Natural History Society, $3^{\text {rd }}$ (Revised) Edition.

Rice, C.G. (1991). The status of Four-horned Antelope Tetracerus quadricornis. Journal of the Bombay Natural History Society 88(1): 63-66.

Ranjitsinh, M.K. (1987). Deer, Antelopes and Bovines. pp.91-100. In: Israel, S. and T. Sinclair (editors). Indian Wildlife. $1^{\text {st }}$ Edition. APA Productions (HK) Ltd.

\section{A Photographic Guide to Snakes and other Reptiles of India By Indraneil Das}

Published by New Holland Publishers (UK) Ltd, Garfield House, 8688 Edgware Road, London W2 2EA, United Kingdom, 2002. 144pp. $(9.5 \times 19 \mathrm{~cm})$.

Price: $£ 7.99$

This is the only coloured photographic guide to snakes and other reptiles of India. The author, Indraneil Das is one of the leading herpetologists, versatile character and a prolific writer. All his experience as a writer can be seen throughout the guide which is presented beautifully for the depth of the subject and language. There are over 270 colour photographs of 243 species of reptiles, including 110 species of snakes, 98 species of lizards, three species of crocodiles and 32 species of turtles and tortoises. The author has provided a brief description of the distinctive characters, habitat, habits and breeding information for all species and, as and when required, for subspecies along with a region-wise distribution.

All the 243 species have been updated with the latest information on valid scientific names. The quality of all the photographs is excellent except for those of Darjeeling Slender Snake (Trachischium fuscus) on page 46 and the Asian Giant Tortoise (Manouria emys) on page 136 which do not show diagnostic features. Breeding data where available has been included and where not available has been so mentioned, which is a very useful documentation. It is surprising, however, that the breeding habits of three species of Bataguridae: Indian Black Turtle (Melanochelys trijuga), Indian Roofed Turtle (Pangshura tectum) and Indian Tent Turtle (P. tentoria) are not provided in the guide although the same author in his own earlier publication (1995: Turtles and Tortoise of India. World Wide Fund) has included the information. Also if a map of India had been provided with its states or regions, it might have been very helpful for the readers to understand the distribution of the species.

In all, the much-needed photographic guide is beautifully produced and a worthy possession for beginners, students and wildlife enthusiasts. The size is quite appropriate for easy handling and carrying in the field.

Raju Vyas, Sayyaji Baug Zoo, Vadodara, Gujarat, India. 